\title{
Prognosis and Survival of Older Patients With Dizziness in Primary Care: A 10-Year Prospective Cohort Study
}

Vincent A. van Vugt, $M D^{1}$

Gïlsün Bas, $M D^{1}$

Jobannes C. van der Wouden, $P b D^{1}$

Jacquelien Dros, MD, $P b D^{2}$

Henk C.P.M. van Weert, MD, $P b D^{2}$

Lucy Yardley, $P b D^{3}$

Jos W. R. Twisk, PbD

Henriëtte E. van der Horst, MD, $\mathrm{PbD}^{1}$

Otto R. Maarsingh, $M D, P b D^{1}$

'Amsterdam UMC, Vrije Universiteit Amsterdam, Department of General Practice and Elderly Care Medicine, Amsterdam Public Health, Amsterdam,

The Netherlands

${ }^{2}$ Amsterdam UMC, location AMC,

Department of General Practice,

Amsterdam Public Health, Amsterdam,

The Netherlands

${ }^{3}$ University of Southampton, Department of Psychology, Southampton, United Kingdom

${ }^{4}$ Amsterdam UMC, Vrije Universiteit Amsterdam, Department of Epidemiology and Biostatistics, Amsterdam Public Health, Amsterdam, The Netherlands

Conflicts of interest: authors report none.

\section{CORRESPONDING AUTHOR}

Vincent A. van Vugt, MD

Amsterdam UMC - location VUMC

Department of General Practice and Elderly

Care Medicine

Van der Boechorststraat 7, Room C-378 1081 BT Amsterdam, The Netherlands v.vanvugt@vumc.nl

\begin{abstract}
PURPOSE The prognosis of older patients with dizziness in primary care is unknown. Our objective was to determine the prognosis and survival of patients with different subtypes and causes of dizziness.
\end{abstract}

METHODS In a primary care prospective cohort study, 417 older adults with dizziness (mean age 79 years) received a full diagnostic workup in 2006-2008. A panel of physicians classified the subtype and primary cause of dizziness. Main outcome measures were mortality and dizziness-related impairment assessed at 10-year follow-up.

RESULTS At 10-year follow-up 169 patients (40.5\%) had died. Presyncope was the most common dizziness subtype $(69.1 \%)$, followed by vertigo $(41.0 \%)$, disequilibrium (39.8\%), and other dizziness (1.7\%). The most common primary causes of dizziness were cardiovascular disease $(56.8 \%)$ and peripheral vestibular disease (14.4\%). Multivariable adjusted Cox models showed a lower mortality rate for patients with the subtype vertigo compared with other subtypes (hazard ratio $[\mathrm{HR}]=0.62 ; 95 \% \mathrm{Cl}, 0.40-0.96)$, and for peripheral vestibular disease vs cardiovascular disease as primary cause of dizziness $(\mathrm{HR}=0.46 ; 95 \% \mathrm{Cl}, 0.25$ 0.84). After 10 years, $47.7 \%$ of patients who filled out the follow-up measurement experienced substantial dizziness-related impairment. No significant difference in substantial impairment was seen between different subtypes and primary causes of dizziness.

CONCLUSIONS The 10-year mortality rate was lower for the dizziness subtype vertigo compared with other subtypes. Patients with dizziness primarily caused by peripheral vestibular disease had a lower mortality rate than patients with cardiovascular disease. Substantial dizziness-related impairment in older patients with dizziness 10 years later is high, and indicates that current treatment strategies by family physicians may be suboptimal.

Ann Fam Med 2020;18:100-109. https://doi.org/10.1370/afm.2478.

\section{INTRODUCTION}

Dizziness is a common problem among older patients in primary care. ${ }^{1}$ The annual prevalence of dizziness in adults ranges from $20 \%$ to $30 \%$ in population-based questionnaire studies. ${ }^{2}$ The frequency and severity of dizziness symptoms generally increases with age. ${ }^{3}$ Diagnosing dizziness and estimating its prognosis is a complex problem for clinicians. ${ }^{4}$ Dizziness is a subjective sensation, only measurable by self-report, that can be caused by a broad array of benign and serious medical conditions. The diagnostic process is particularly challenging in older patients with dizziness, because the cause of their dizziness is usually multifactorial., ${ }^{5,6}$ Dizziness is often divided into 4 major subtypes: vertigo, presyncope (also known as light-headedness), disequilibrium (also known as unsteadiness), and other dizziness. ${ }^{7-9}$ Different subtypes are generally associated with different organ systems such as peripheral vestibular disease or cardiovascular disease. ${ }^{4,5}$ Determining the cause of dizziness might help in choosing an appropriate treatment.

Over $80 \%$ of patients experiencing dizziness in the Netherlands, United Kingdom, and United States of America are primarily treated by 
their primary care physician and are never referred to a specialist..$^{10-12}$ Nevertheless, most diagnostic and prognostic studies investigated patients in secondary and tertiary care settings. ${ }^{13-15}$ We started a prospective cohort study in 2006 to gain more insight into the diagnosis and prognosis of older patients with dizziness in primary care. ${ }^{5}$ This study yielded new insights into diagnosing dizziness in primary care that have been reported in previous publications. ${ }^{5,16,17}$ By following these patients over a 10-year period we are now able to investigate the long-term prognosis of older patients with dizziness in primary care. Dizziness has been associated with increased premature mortality ${ }^{18}$ and substantial functional impairment, ${ }_{1}^{16,19}$ but it is unclear if these risks are equal for all subtypes and causes of dizziness. More specific prognostic information may help family physicians to identify and treat high-risk patients in a timely manner. The objective of this study is to investigate if and how the dizziness subtypes and primary causes of dizziness are associated with mortality and dizziness-related impairment 10 years later.

\section{METHODS}

\section{Participants and Baseline Assessments}

The details of the inclusion and baseline data collection of the Dizziness In Elderly Patients cohort were reported previously. ${ }^{5,20}$ In summary, we prospectively identified 417 older primary care patients (aged $\geq 65$ years) with dizziness that had been present for at least 2 weeks from June 2006 through January 2008. An international Delphi procedure was used to determine a comprehensive list of diagnostic tests fo dizziness. At inclusion all patients received a full diagnostic workup. We recorded sociodemographic characteristics, smoking habits, alcohol intake, current use of medication, medical history, characteristics of dizziness, and the use of any hearing, seeing, or walking aids. All patients completed the Primary Care Evaluation of Mental Disorders Patient Health Questionnaire, a self-administered instrument to assess psychiatric disorders. ${ }^{21,22}$ During the physical examination we assessed the following organ systems: cardiovascular (pulse, blood pressure, orthostatic hypotension measurement), locomotor (orthopedic screening of lower limbs, tandem gait, timed up-and-go test), neurologic (tendon reflexes, Semmes-Weinstein monofilament test), vestibular (otoscopy, Dix-Hallpike maneuver, audiometry) and visual (Landolt rings eye chart). We also measured hemoglobin and non-fasting blood glucose levels in the laboratory and performed an electrocardiogram and continuous event recording on indication. Next, a panel consisting of a family physician, a geriatrician, and a nursing home physician independently reviewed the data for each patient to ascertain dizziness subtype and (major and minor contributory) causes of dizziness. Every participant was definitively categorized into 1 or more of the 4 dizziness subtypes by means of a majority decision (at least 2 of 3 panel members had to agree). In addition, the panel classified the relative contribution (from 0\% to 100\%) of causes of dizziness for each patient from a list of 9 possible groups of medical conditions: cardiovascular disease (including cerebrovascular disease), peripheral vestibular disease, psychiatric disease, locomotor disease, neurologic disease (excluding cerebrovascular disease), adverse drug effect, metabolic or endocrine conditions, impaired vision, and other cause. All causes that were scored higher than $0 \%$ by at least 2 out of 3 panel members were considered as a contributory cause. The medical condition with the highest mean contributing percentage across all 3 reviewers was identified as the primary cause of dizziness. ${ }^{5}$

The study protocol was approved by the Medical Ethics Committee of the VU University Medical Center. All patients included in the study provided written informed consent.

\section{Follow-Up}

Our primary outcomes are mortality and substantial impairment due to dizziness. The follow-up measurements took place from October 2016 through January 2018, approximately 10 years after the start of the study. Deaths were identified through family physician (FP) records and reports by next of kin. Patients lost to follow-up were censored at the last day confirmed to be alive. When the exact day of death was unclear, we entered the middle of the known month or year as date of death. We used the Dizziness Handicap Inventory (DHI) to assess impairment due to dizziness. ${ }^{23}$ The $\mathrm{DHI}$ is the most widely used questionnaire for dizziness and can be used to quantify the self-perceived impact of dizziness on daily life. ${ }^{24}$ It has been shown to have good construct validity, high internal consistency, and satisfactory test-retest reliability. ${ }^{23,26,27}$ The questionnaire consists of 25 questions (score range $0-100$ ), higher scores correspond with more handicapping effects due to dizziness. A total DHI score of 30 or higher is generally believed to indicate substantial dizziness-related impairment. ${ }^{25,28,29}$ Participants were asked to fill out a DHI questionnaire at baseline, after 6 months, ${ }^{30}$ and after 10 years. Participants who were mentally or physically unable to complete a questionnaire were excluded.

\section{Statistical Analyses}

To analyze the relationship between dizziness and mortality, first we calculated the time from the date of enrollment in the Dizziness In Elderly Patients cohort to date of death or the end of follow-up, whichever 
came first. Second, we generated Kaplan-Meier survival curves for the 4 dizziness subtypes and compared them with log rank tests. Third, we used Cox proportional hazard models to estimate hazardratios with $95 \%$ CIs for the 4 dizziness subtypes and for the 9 primary causes. Based on previous studies and

Table 1. Baseline Characteristics of Patients $(\mathrm{N}=417)$

\begin{tabular}{|c|c|c|c|}
\hline Characteristic & Value & Characteristic & Value \\
\hline Demographics & & Dizziness characteristics (continued) & \\
\hline Age, mean (range), y & $79(65.0-95.0)$ & Frequency, No. (\%) & \\
\hline Sex, female, No. (\%) & $307(73.6)$ & Continuous & $42(10.1)$ \\
\hline Ethnic background, No. (\%) & & Daily & $195(46.8)$ \\
\hline Dutch native & $342(82.0)$ & Weekly & $105(25.2)$ \\
\hline Western immigrant & $31(7.4)$ & Monthly & $50(12.0)$ \\
\hline Non-Western immigrant & $44(10.6)$ & Annually & $25(6.0)$ \\
\hline Level of education & & Duration of symptoms, No. (\%) & \\
\hline Low, No. (\%) & $297(71.2)$ & $<10$ seconds & $110(26.4)$ \\
\hline Middle or high, No. (\%) & $120(28.8)$ & $10-60$ seconds & $78(18.7)$ \\
\hline Living situation, community-dwelling, No. (\%) & $397(95.2)$ & Several minutes & $71(17.0)$ \\
\hline Smoking, No. (\%) & $62(14.9)$ & Several minutes to 1 hour & $22(5.3)$ \\
\hline Medical history & & $>1$ hour & $35(8.4)$ \\
\hline Cardiovascular disease, No. (\%) & & Constant when present & $26(6.2)$ \\
\hline Hypertension & $239(57.3)$ & Combination of durations & $75(18.0)$ \\
\hline Ischemic heart disease & $111(26.7)$ & Diagnostic tests & \\
\hline Arrhythmia & $94(22.5)$ & Psychiatric diagnosis according to & \\
\hline Heart valve disease & $58(13.9)$ & PRIME-MD PHQ, No. (\%) & \\
\hline Myocardial infarction & $57(13.7)$ & Major depressive syndrome & $53(12.7)$ \\
\hline Ear, nose, and throat disease, No. (\%) & & Panic disorder & $19(4.6)$ \\
\hline Benign paroxysmal positional dizziness & $40(9.8)$ & Other anxiety syndrome & $42(10.1)$ \\
\hline Ménière's disease & $27(6.5)$ & MDS, PD, or OAS & $90(21.6)$ \\
\hline Acoustic neuroma & $1(0.2)$ & Panel evaluation & \\
\hline Neurologic disease, No. (\%) & & Dizziness subtype, No. (\%) & \\
\hline Migraine & $79(18.9)$ & Presyncope & $288(69.1)$ \\
\hline Stroke & $66(15.8)$ & Vertigo & $171(41.0)$ \\
\hline Parkinson disease & $7(1.7)$ & Disequilibrium & $166(39.8)$ \\
\hline Epilepsy & $6(1.4)$ & Other dizziness & $7(1.7)$ \\
\hline Multiple sclerosis & $1(0.2)$ & No consensus & $16(3.8)$ \\
\hline Locomotor disease, No. (\%) & & $\begin{array}{l}\text { Number of dizziness subtypes per } \\
\text { participant, No. (\%) }\end{array}$ & \\
\hline Osteoarthritis of the knee & $120(28.8)$ & 1 & $217(52.0)$ \\
\hline Osteoarthritis of the hip & $78(18.7)$ & 2 & $137(32.9)$ \\
\hline Psychiatric illness, No. (\%) & & 3 & $47(11.2)$ \\
\hline Depressive disorder & $101(24.2)$ & No consensus & $16(3.8)$ \\
\hline Anxiety disorder & $75(18.0)$ & Primary cause of dizziness, No. (\%) & \\
\hline Other, No. (\%) & & Cardiovascular disease (including & $237(56.8)$ \\
\hline Diabetes & $78(18.7)$ & cerebrovascular disease) & \\
\hline Cataract & $199(47.7)$ & Peripheral vestibular disease & $60(14.4)$ \\
\hline Macular degeneration & $27(6.5)$ & \multirow{10}{*}{$\begin{array}{l}\text { Other (psychiatric illness, locomotor disease, } \\
\text { neurologic disease [excluding stroke], } \\
\text { adverse drug effect, impaired vision, } \\
\text { metabolic or endocrine conditions, or } \\
\text { unclear disease) }\end{array}$} & $120(28.8)$ \\
\hline Drugs per patient, mean (SD) & $4(3.0)$ & & \\
\hline Polypharmacy (>5 drugs), No. (\%) & $138(33.0)$ & & \\
\hline Dizziness characteristics & & & \\
\hline Onset of dizziness symptoms, No. (\%) & & & \\
\hline 2-4 weeks & $30(7.2)$ & & \\
\hline $1-6$ months & $98(23.5)$ & & \\
\hline 6-24 months & $110(26.4)$ & & \\
\hline 2-10 years & $120(28.8)$ & & \\
\hline$>10$ years & $59(14.1)$ & & \\
\hline
\end{tabular}


Table 2. Hazard Ratios of Mortality in Participants for Different Dizziness Subtypes

\begin{tabular}{|c|c|c|c|c|c|c|}
\hline \multirow[b]{2}{*}{$\begin{array}{l}\text { Dizziness } \\
\text { Subtype }\end{array}$} & \multirow[b]{2}{*}{$\begin{array}{l}\text { No. of } \\
\text { Persons }\end{array}$} & \multirow[b]{2}{*}{$\begin{array}{l}\text { No. of } \\
\text { Deaths }\end{array}$} & \multirow[b]{2}{*}{$\begin{array}{l}\text { Person } \\
\text { Years }\end{array}$} & \multirow{2}{*}{$\begin{array}{c}\text { Incidence Rate } \\
(95 \% \mathrm{Cl}) \text { per } 1,000 \\
\text { Person Years }\end{array}$} & \multicolumn{2}{|c|}{$\begin{array}{l}\text { Compared With Participants } \\
\text { Without This Subtype }\end{array}$} \\
\hline & & & & & $\begin{array}{l}\text { Unadjusted HR } \\
(95 \% \mathrm{Cl})\end{array}$ & $\begin{array}{l}\text { Adjusted HR } \\
(95 \% \mathrm{Cl})^{\mathrm{a}}\end{array}$ \\
\hline Vertigo & 171 & 58 & 1,213 & $47.81(36.30-61.80)$ & $0.64(0.47-0.88)$ & $0.62(0.40-0.96)$ \\
\hline Presyncope & 288 & 126 & 1,903 & $66.21(55.15-78.83)$ & $1.36(0.96-1.92)$ & $1.23(0.82-1.85)$ \\
\hline Disequilibrium & 161 & 65 & 1,039 & $62.55(48.27-79.72)$ & $1.09(0.80-1.49)$ & $1.26(0.85-1.87)$ \\
\hline Other dizziness & 7 & 2 & 48 & $41.70(5.50-150.63)$ & $0.67(0.17-2.71)$ & $0.76(0.18-3.18)$ \\
\hline
\end{tabular}

$\mathrm{HR}=$ hazard ratio; PRIME-MD PHQ = Primary Care Evaluation of Mental Disorders Patient Health Questionnaire.

a Adjusted for age, sex, ethnicity, level of education, preexistent cardiovascular disease and/or stroke, diabetes, polypharmacy (defined as $>5$ types of daily medication), an anxiety or depressive disorder according to the PRIME-MD PHQ, and the number of assigned dizziness subtypes.

feasibility, we prespecified the following potential confounders: age, ${ }^{18,31-33}$ sex $_{1}^{18,31-33}$ ethnicity, ${ }_{1}^{18,31}$ level of education, ${ }_{1}^{18,31}$ preexistent cardiovascular disease, ${ }^{18,32}$ preexistent stroke, ${ }^{18,32}$ preexistent diabetes, ${ }_{1}^{18,30}$ polypharmacy (defined as $>5$ types of daily medication), ${ }^{30,32,34}$ a comorbid anxiety or depressive disorder at baseline according to the Primary Care Evaluation of Mental Disorders Patient Health Questionnaire, $30-32,35$ and the number of assigned dizziness subtypes. The 10 potential confounders are described in more detail in Supplemental Appendix 1, http://www.AnnFamMed. org/content/18/2/100/suppl/DC1/. We adjusted for the prespecified potential confounders by adding them as covariates to the models. To analyze the relationship with dizziness-related impairment, we used total DHI scores at baseline, 6-month follow-up, and 10-year follow-up as outcomes. These scores were analyzed both as a continuous variable and a dichotomous variable (ie, no substantial impairment [DHI scores 0-29] and substantial impairment [DHI scores 30-100]). For the continuous outcome we used linear mixed model analysis, and for dichotomous outcome we used logistic generalized estimating equations (GEE analysis). ${ }^{36}$ Both methods take into account the dependence of the observations within the patient. In both analyses, we adjusted for the same prespecified potential confounders as for the Cox proportional hazard models. We also conducted 1 exploratory analysis and 2 post hoc sensitivity analyses to test the robustness of our findings. In the exploratory analysis, we graphically illustrated how participants who filled out the 10 -year DHI measurement tracked over all 3 time points. In the first sensitivity analysis, the dizziness subtype in patients had to be agreed upon by all 3 panel physicians (unanimous decision) instead of at least 2 out of 3 panel physicians (majority decision). In the second sensitivity analysis, only participants who were assigned to 1 subtype were included in the analyses. IBM SPSS Statistics version 22.0 (IBM Corp) and Stata version 14.1 (StataCorp LLC) were used for statistical analyses.

\section{RESULTS}

\section{Study Participants}

The Dizziness In Elderly Patients cohort consisted of 417 participants. At baseline, the mean age of participants was 79 years (range 65-95); 73.6\% were female, and $69.3 \%$ had experienced dizziness for more than 6 months. Presyncope was the most common dizziness subtype $(69.1 \%)$, followed by vertigo $(41.0 \%)$, disequilibrium (39.8\%), and other dizziness (1.7\%). Patients were assigned by the panel to 1 subtype $(52.0 \%), 2$ subtypes $(32.9 \%), 3$ subtypes $(11.2 \%)$ or no subtype at all (3.8\%). According to the panel, the most common primary causes of dizziness were cardiovascular disease $(56.8 \%)$ and peripheral vestibular disease (14.4\%). The baseline characteristics are presented in Table 1. After 10 years, 103 participants (24.7\%) filled out a DHI that was analyzed for dizziness-related impairment. Of the other participants, 169 (40.5\%) had died, 86 (20.6\%) had no known address or did not respond to the questionnaire, $30(7.2 \%)$ had serious cognitive disorders, $21(5.0 \%)$ were contacted but refused to participate, and $8(1.9 \%)$ had severe somatic disorders, such as a terminal illness, that prevented them from filling out a questionnaire.

\section{Mortality}

At 10-year follow-up 169 deaths were recorded (40.5\%). The association between mortality and dizziness subtypes is shown in Table 2, before and after adjusting for potential confounders. Participants with the subtype vertigo had a lower 10-year mortality risk (hazard ratio $[\mathrm{HR}]=0.62 ; 95 \% \mathrm{CI}, 0.40-0.96)$ than participants with other dizziness subtypes. The Kaplan-Meier survival curve in Figure 1 further illustrates this association. Table 3 and Figure 2 show the association between mortality and the primary cause of dizziness, before and after adjusting for potential confounders. Dizziness due to peripheral vestibular disease was associated with a lower hazard of death $(\mathrm{HR}=0.46 ; 95 \% \mathrm{CI}, 0.25-0.84)$ than dizziness due to cardiovascular disease. 
Figure 1. Kaplan-Meier survival curves for patients assigned to dizziness subtype vertigo. ${ }^{a}$
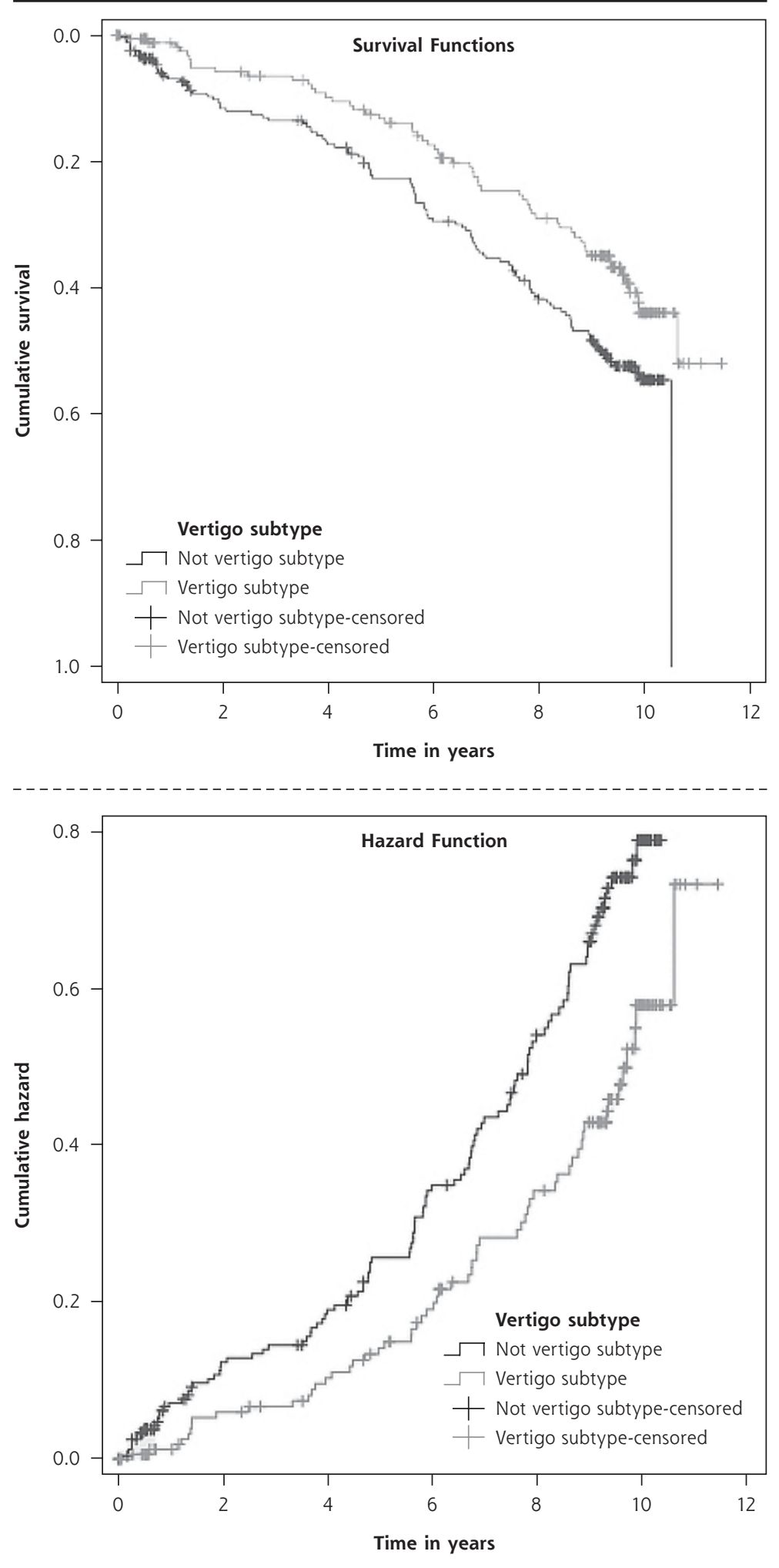

a Panel assigned subtype by at least 2 out of 3 panel members. Patients with vertigo compared with patients who were not assigned to this subtype.
Dizziness-Related Impairment

An overview of DHI scores for each measurement is presented in Table 4 . At baseline, the mean DHI score was 36.3 and $60.7 \%$ of participants had a DHI score $\geq 30$ which constitutes substantial impairment due to dizziness. After 10 years, the average DHI score was 31.1 and $47.4 \%$ of the 103 participants still experienced substantial dizziness-related impairment. Approximately one-third (34\%) of these participants never reported substantial dizziness-related impairment, while one-fourth (26\%) experienced it at every measurement.

Table 5 shows the association between dizziness subtypes and dizziness-related impairment 10 years later. The dizziness subtype presyncope was associated with a lower mean DHI score than seen in participants without this subtype, but did not have a significantly lower odds ratio at substantial dizzinessrelated impairment. Other subtypes and primary causes of dizziness, such as cardiovascular or peripheral vestibular disease, were not significantly associated with DHI scores. The relationship between these primary causes and impairment is shown in Table 6.

\section{Exploratory and Sensitivity Analyses}

In Supplemental Appendix 2 (http://www.AnnFamMed.org/ content/18/2/100/suppl/DC1/), we listed the baseline characteristics of patients who were still alive or had died during follow-up. Compared with deceased patients, patients alive at follow-up were younger, more often female, and used less medication. In Supplemental Appendix 3 (http://www.AnnFamMed.org/ content/18/2/100/suppl/DC1/), we listed the baseline characteristics of patients alive at follow-up who filled out the 10-year DHI measurement vs patients who did not. In an exploratory analysis, we used the total DHI score of each of the 103 participants 
Table 3. Hazard Ratios of Mortality in Participants for Different Primary Causes of Dizziness

\begin{tabular}{lcccccc}
\hline $\begin{array}{l}\text { Primary Cause of } \\
\text { Dizziness }\end{array}$ & $\begin{array}{c}\text { No. of } \\
\text { Persons }\end{array}$ & $\begin{array}{c}\text { No. of } \\
\text { Deaths }\end{array}$ & $\begin{array}{c}\text { Person } \\
\text { Years }\end{array}$ & $\begin{array}{c}\text { Incidence Rate per } \\
\mathbf{1 , 0 0 0} \text { Person Years } \\
\mathbf{( 9 5 \% ~ C l )}\end{array}$ & $\begin{array}{c}\text { Unadjusted HR } \\
\mathbf{( 9 5 \% ~ C l )}\end{array}$ & $\begin{array}{c}\text { Adjusted HR } \\
\mathbf{( 9 5 \% ~ C l )}\end{array}$ \\
\hline Cardiovascular disease & 237 & 113 & 1,495 & $75.61(62.31-90.90)$ & Reference & Reference \\
Peripheral vestibular disease & 60 & 13 & 495 & $26.25(13.98-44.89)$ & $0.32(0.18-0.56)$ & $0.46(0.25-0.84)$ \\
Psychiatric disease & 41 & 15 & 264 & $56.88(31.84-93.82)$ & $0.72(0.42-1.20)$ & $0.89(0.49-1.61)$ \\
Other causes $^{b}$ & 79 & 28 & 516 & $54.42(36.04-78.38)$ & $0.69(0.46-1.05)$ & $0.66(0.43-1.02)$ \\
\hline
\end{tabular}

$\mathrm{HR}=$ hazard ratio; PRIME-MD PHQ = Primary Care Evaluation of Mental Disorders Patient Health Questionnaire.

${ }^{a}$ Adjusted for age, sex, ethnicity, level of education, preexistent cardiovascular disease and/or stroke, diabetes, polypharmacy (defined as $>5$ types of daily medication), an anxiety or depressive disorder according to the PRIME-MD PHQ and the number of assigned dizziness subtypes.

${ }^{b}$ Locomotor disease $(n=15)$, neurologic disease (excluding cerebrovascular disease) $(n=12)$, adverse drug effect $(n=10)$, metabolic or endocrine conditions ( $\left.n=3\right)$, impaired vision $(n=2)$, other causes $(n=3)$, and unclear cause $(n=34)$.

at the baseline, 6-month, and 10-year measurements to analyze how scores tracked over time. As graphically shown in Supplemental Figure 1 (http://www. AnnFamMed.org/content/18/2/100/suppl/DC1/), no clear pattern can be identified in these scores.

In the first sensitivity analysis, the dizziness subtype in patients had to be agreed upon by all 3 panel physicians (unanimous decision) instead of at least 2 out of 3 panel physicians (majority decision). Supplemental Tables 1 and 2 (http://www.AnnFamMed.org/ content/18/2/100/suppl/DC1/) show the association of unanimous dizziness subtypes with mortality and dizziness-related impairment 10 years later. The associations of unanimous subtypes with mortality were comparable to the main analysis, but failed to reach statistical significance due to larger CIs. Unlike the majority decision subtype presyncope, the unanimous subtype presyncope was not associated with DHI score. In the second sensitivity analysis, only participants who were assigned to 1 subtype $(n=217)$ were included in the analyses. Supplementary Tables 3 and 4 (http://www.AnnFamMed.org/content/18/2/100/suppl/ DC1/) show the associations between dizziness subtypes with mortality and dizziness-related impairment 10 years later in this group of patients. The associations are similar to the main analysis, but due to the small number of patients in this analysis no significant associations were seen.

\section{DISCUSSION}

\section{Summary}

In a prospective 10 -year cohort study in primary care of older patients with panel-diagnosed dizziness, we analyzed the association of different dizziness subtypes and primary causes of dizziness with mortality and dizziness-related impairment. The dizziness subtype vertigo was associated with a lower mortality rate in the 10-year period than the subtypes presyncope, disequilibrium, and other dizziness. Dizziness due to peripheral vestibular disease was associated with a lower risk of mortality in 10 years than dizziness due to cardiovascular disease. Although subtypes and primary causes of dizziness were not significantly associated with the development of substantial impairment due to dizziness, participants with the presyncope subtype did have relatively less dizziness symptoms 10 years later. A final notable finding was that even though dizziness is often seen as a self-limiting affliction, almost one-half of all participants who filled out the 10-year measurement felt substantially impaired due to dizziness.

\section{Comparison With Existing Literature}

In a large American population-based cohort study the presence of dizziness in the last 12 months was an independent risk factor for mortality. ${ }^{18}$ After adjusting for relevant covariates including age, ethnicity, race, sex, diabetes, cardiovascular disease, cerebrovascular disease, and cancer, being dizzy was a risk factor for early mortality comparable to leading causes of death such as cardiovascular disease and cancer. ${ }^{18}$ This is the first study that examines differences in mortality for subtypes and causes of dizziness. We found that the vertigo subtype and dizziness primarily due to peripheral vestibular disease were associated with a lower mortality rate in a 10 -year period. Intuitively, this might not be surprising because vertigo patients and patients with peripheral vestibular disease are younger on average and more often female than presyncope patients and patients with cardiovascular disease. ${ }^{5}$ Nevertheless, these associations remained significant after adjusting for age, sex, and other confounders.

Research on the prognosis of dizziness in primary care is scarce ${ }^{37}$ Most epidemiological studies in community-dwelling older adults have been cross-sectional. ${ }^{2}$ Only 3 long-term prospective cohort studies ( $>1$ year) were identified and none of these 


\section{Figure 2. Kaplan-Meier survival curves for patients with different} primary causes of dizziness.
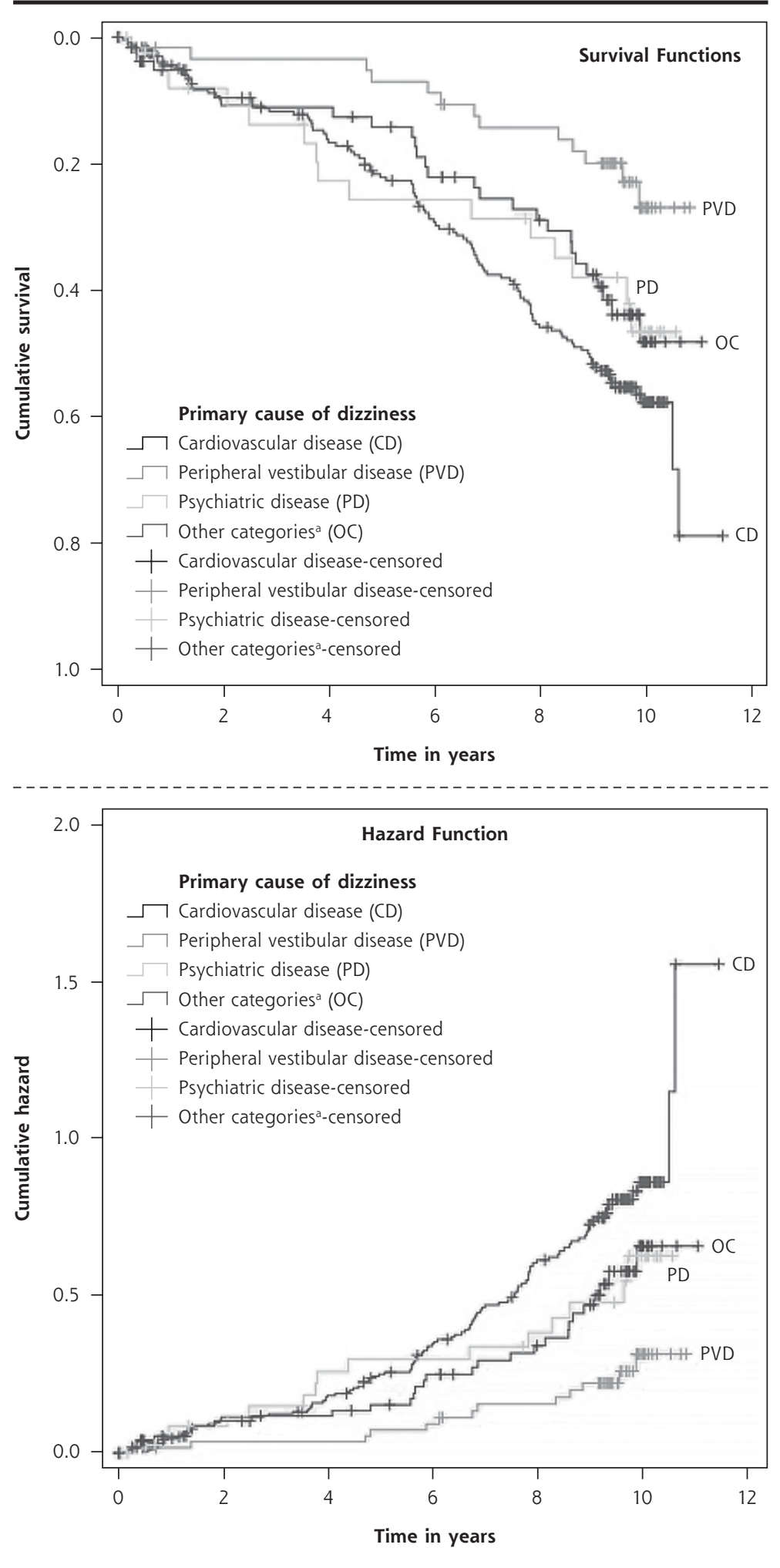

a Locomotor disease, neurologic disease (excluding cerebrovascular disease), adverse drug effect, metabolic or endocrine conditions, impaired vision, other causes, and unclear cause. studies measured dizziness-related impairment longitudinally. ${ }^{31-33}$ Our study found less dizziness-related impairment in presyncope patients, but not less substantial dizzinessrelated impairment $(\mathrm{DHI} \geq 30)$. This is the first prognostic longitudinal study that identifies a difference in dizziness-related impairment between subtypes. These results should be interpreted with caution though, because they might be explained by the higher mortality rate in the presyncope group (survivor bias). ${ }^{38}$ No other associations between dizzinessrelated impairment and subtypes or primary causes of dizziness were identified. Overall, $47.7 \%$ of patients who filled out the 10-year measurement experienced substantial dizzinessrelated impairment. This suggests that current treatment strategies in primary care may be suboptimal.

\section{Strengths and Limitations}

Our study has several strengths. An extensive diagnostic set of tests for dizziness was developed based on a systematic review and a Delphi procedure with experts in the field..$^{20}$ All participants completed this workup and were then diagnosed by a panel of 3 physicians, which is the preferred diagnostic method when a gold standard is not available ${ }^{39}$ Considering this time-intensive inclusion process, we managed to include a sizeable cohort of 417 participants.

There are also some limitations. First, Drachman's categorization in 4 subtypes is still widely used, but not undisputed. There is a risk of misdiagnosis when we only focus on the way patients describe their dizziness, eg, a "spinning sensation" or "light-headedness." At the moment, a paradigm shift in diagnosing dizziness is taking place which focuses less on the patients' description of their dizziness sensation and more on timing and triggers. ${ }^{40,41}$ New terminology has been proposed, but in most guidelines dizziness is still categorized according to the classical 4 subtypes. ${ }^{8,9}$ Our 
Table 4. DHI Scores and Patterns of Substantial Impairment at Follow-Up

\begin{tabular}{|c|c|c|c|}
\hline DHI Score & $\begin{array}{l}\text { No. of } \\
\text { Persons }\end{array}$ & $\begin{array}{c}\text { Mean } \\
\text { DHI Score, } \\
\text { No. (SD) }\end{array}$ & $\begin{array}{l}\text { Sustantially } \\
\text { Impaired } \\
\text { (DHI } \geq 30), \%\end{array}$ \\
\hline Baseline $(n=415)$ & 415 & $36.3(19.9)$ & 60.7 \\
\hline 6-month follow-up $(n=374)$ & 374 & $28.0(23.6)$ & 42.2 \\
\hline 10-year follow-up $(n=103)$ & 103 & $31.1(25.0)$ & 47.7 \\
\hline \multicolumn{4}{|c|}{$\begin{array}{l}\text { Patterns of substantial impairment due } \\
\text { to dizziness }(\mathrm{DHI} \geq 30)(\mathrm{n}=100)^{\mathrm{a}}\end{array}$} \\
\hline Never substantially impaired & & & 34 \\
\hline $\begin{array}{l}\text { Substantially impaired at } 1 \text { or } \\
2 \text { measurements }\end{array}$ & & & 40 \\
\hline $\begin{array}{l}\text { Substantially impaired at all } \\
3 \text { measurements }\end{array}$ & & & 26 \\
\hline \multicolumn{4}{|l|}{ DHI = dizziness handicap inventory. } \\
\hline \multicolumn{4}{|c|}{$\begin{array}{l}\text { a Only participants who completed a DHI at baseline, } 6 \text {-month, and 10-year follow-up were included } \\
\text { in this analysis. Although } 103 \text { participants filled out the } 10 \text {-year measurement, } 3 \text { of these participants } \\
\text { missed the } 6 \text {-month measurement. }\end{array}$} \\
\hline
\end{tabular}

panel did not base their diagnosis on the patients' description of dizziness but on a comprehensive set of diagnostic tests and an extensive medical history including timing and triggers. Therefore, future changes in nomenclature and diagnostic procedures will not directly invalidate the results of our study. General practitioners will continue to have to assess the primary cause of dizziness and identify patients at risk for persistent impairment due to dizziness. ${ }^{28}$ Second, we adjusted our analyses for 10 potential confounders. To limit the risk of bias, covariates were defined before we conducted our analyses. We chose these confounders based on feasibility and a literature review of previous studies. ${ }^{18,30-35}$

Table 5. Mean Differences in DHI Scores and Odds Ratios to Develop Substantial Dizziness-Related Impairment After 10 Years for Dizziness Subtypes $(N=103)$

\begin{tabular}{|c|c|c|c|c|c|c|c|}
\hline \multirow[b]{2}{*}{ Subtypes } & \multirow[b]{2}{*}{$\begin{array}{l}\text { No. of } \\
\text { Persons }\end{array}$} & \multicolumn{2}{|c|}{ Baseline Values } & \multicolumn{4}{|c|}{ Compared With Participants Without This Subtype } \\
\hline & & $\begin{array}{l}\text { Mean DHI } \\
\text { (SD) }\end{array}$ & $\begin{array}{c}\mathrm{DHI} \geq 30, \\
\%\end{array}$ & $\begin{array}{l}\text { Unadjusted } \\
\text { MD in DHI Score } \\
(95 \% \mathrm{Cl})\end{array}$ & $\begin{array}{l}\text { Adjusted } \\
\text { MD in DHI Score } \\
(95 \% \mathrm{Cl})^{\mathrm{a}}\end{array}$ & $\begin{array}{c}\text { Unadjusted } \\
\text { OR for } \mathrm{DHI} \geq 30 \text {, } \\
\text { OR }(95 \% \mathrm{Cl})\end{array}$ & $\begin{array}{l}\text { Adjusted OR } \\
\text { for } \mathrm{DHI} \geq 30 \text {, } \\
\text { OR }(95 \% \mathrm{Cl})^{\circ}\end{array}$ \\
\hline Vertigo & 47 & $34.6(19.3)$ & 48.9 & $\begin{array}{c}8.24 \\
(1.12-15.37)\end{array}$ & $\begin{array}{c}5.13 \\
(-2.66 \text { to } 12.91)\end{array}$ & $\begin{array}{c}1.25 \\
(0.64-2.43)\end{array}$ & $\begin{array}{c}1.15 \\
(0.44-2.96)\end{array}$ \\
\hline Presyncope & 68 & $29.5(16.5)$ & 47.1 & $\begin{array}{c}-3.74 \\
(-11.39 \text { to } 3.90)\end{array}$ & $\begin{array}{c}-8.07 \\
(-16.03 \text { to }-0.10)\end{array}$ & $\begin{array}{c}0.89 \\
(0.44-1.79)\end{array}$ & $\begin{array}{c}0.54 \\
(0.21-1.40)\end{array}$ \\
\hline Disequilibrium & 66 & $33.0(18.3)$ & 51.4 & $\begin{array}{c}6.20 \\
(-1.29 \text { to } 13.69)\end{array}$ & $\begin{array}{c}2.84 \\
(-5.80 \text { to } 11.49)\end{array}$ & $\begin{array}{c}1.73 \\
(0.85-3.49)\end{array}$ & $\begin{array}{c}1.73 \\
(0.64-4.66)\end{array}$ \\
\hline Other dizziness & 3 & $46.0(21.1)$ & 66.7 & $\begin{array}{c}2.15 \\
(-19.48 \text { to } 23.78)\end{array}$ & $\begin{array}{c}0.47 \\
(-18.50 \text { to } 19.43)\end{array}$ & $\begin{array}{c}1.08 \\
(0.16-7.15)\end{array}$ & $\begin{array}{c}0.87 \\
(0.18-4.21)\end{array}$ \\
\hline
\end{tabular}

$\mathrm{DHI}=$ dizziness handicap inventory; $\mathrm{MD}=$ mean difference; $\mathrm{OR}=$ odds ratio; PRIME-MD PHQ = Primary Care Evaluation of Mental Disorders Patient Health Questionnaire

a Adjusted for age, sex, ethnicity, level of education, preexistent cardiovascular disease and/or stroke, diabetes, polypharmacy (defined as $>5$ types of daily medication), an anxiety or depressive disorder according to the PRIME-MD PHQ, and the number of assigned dizziness subtypes.

Table 6. Mean Differences in DHI Scores and Odds Ratios to Develop Substantial Dizziness-Related Impairment After 10 Years for the Primary Cause of Dizziness $(N=103)$

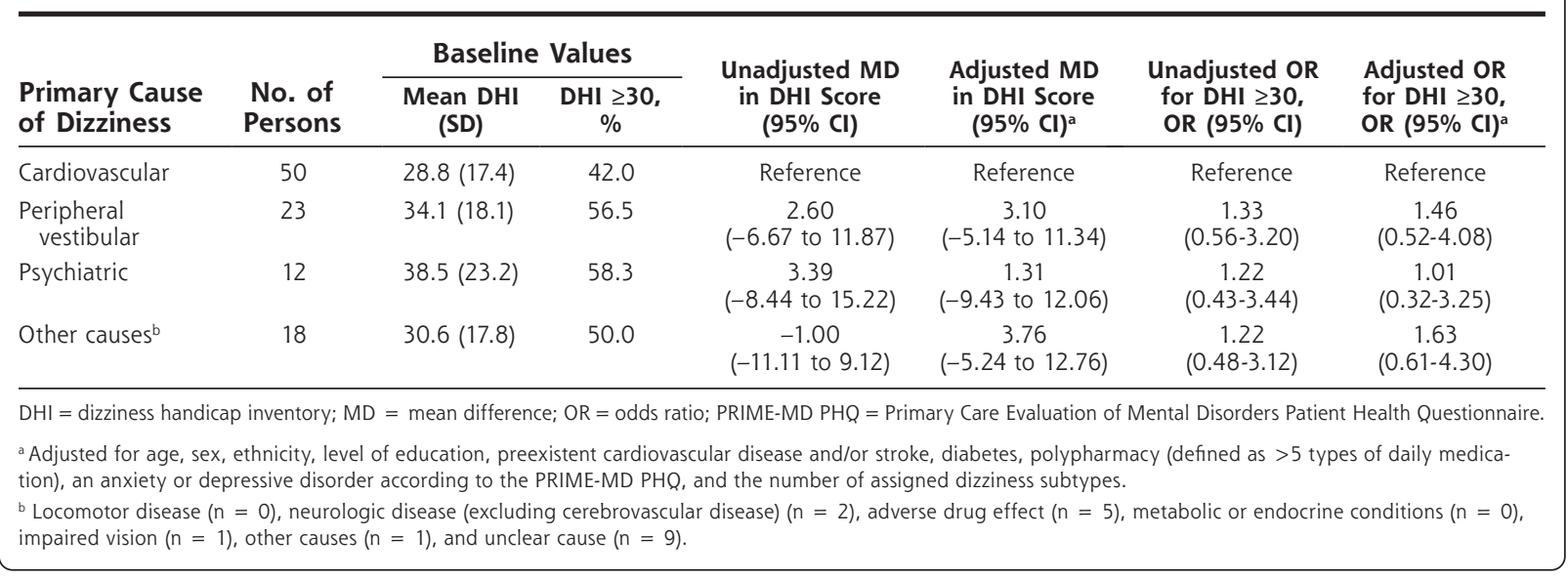


Although we have attempted to adjust for the most relevant confounders, we cannot exclude the possibility that unidentified factors influenced our primary outcomes. Third, due to the advanced age of our participants at inclusion, only a limited subset was available for analysis of dizziness-related impairment 10 years later. This small sample size might be why we found no significant differences between different primary causes of dizziness. In the main analysis, the dizziness subtype presyncope, as determined by a majority decision of the panel, was associated with a lower mean DHI score 10 years later. In a sensitivity analysis that only assigned patients to a subtype if all 3 panel members agreed, however, the subtype presyncope was not associated with the DHI score. This indicates that the results we found on the association between different dizziness subtypes and long-term dizziness-related impairment should be interpreted with care.

\section{Conclusions and Implications for Research and/or Practice}

These results provide new insights in the prognosis of older patients with dizziness in primary care. The 10-year survival was higher for patients with the subtype vertigo compared with other subtypes. Patients with dizziness primarily caused by peripheral vestibular disease also lived longer than patients with dizziness caused by vascular disease. Differences in subtype and primary cause of dizziness were not associated with substantial dizziness-related impairment 10 years later. The large percentage of older patients with dizziness that experience substantial dizziness-related impairment 10 years later indicates that current treatment strategies in primary care may be suboptimal.

To read or post commentaries in response to this article, see it online at http://www.AnnFamMed.org/content/18/2/100.

Key words: aged; dizziness; family practice; mortality; vertigo

Submitted March 5, 2019; submitted, revised, July 5, 2019; accepted July 19, 2019.

Author Contributions: V.A.vV. and O.R.M. developed the concept of the article. O.R.M., J.D., G.B., and V.A.vV. collected the data. V.A.vV. and J.W.R.T. analyzed the data. V.A.vV. wrote the first substantial draft of the article and is the guarantor. J.C.vdW., H.E.vdH., H.C.P.M.vW. and L.Y. critically revised the manuscript. All authors read and approved the final manuscript.

Funding support: This study was funded by an Amsterdam Public Health Aging And Later Life innovation grant and by the Netherlands Organisation for Health Research and Development (ZonMW, No. 4200.0018), The Hague. The sponsors did not participate in the study design, data collection, analysis, interpretation, or the preparation or submission of this report.

Acknowledgments: We would like to thank Welmoed Kreb for her help in collecting the 10-year follow-up data.
Supplemental materials: Available at http://www.AnnFamMed. org/content/18/2/100/suppl/DC1/.

\section{References}

1. Bailey KE, Sloane PD, Mitchell M, Preisser J. Which primary care patients with dizziness will develop persistent impairment? Arch Fam Med. 1993;2(8):847-852.

2. Neuhauser HK. The epidemiology of dizziness and vertigo. Handb Clin Neurol. 2016;137:67-82.

3. Jönsson R, Sixt E, Landahl S, Rosenhall U. Prevalence of dizziness and vertigo in an urban elderly population. J Vestib Res. 2004;14(1): 47-52.

4. Sloane PD, Coeytaux RR, Beck RS, Dallara J. Dizziness: state of the science. Ann Intern Med. 2001;134(9 Pt 2):823-832.

5. Maarsingh OR, Dros J, Schellevis FG, et al. Causes of persistent dizziness in elderly patients in primary care. Ann Fam Med. 2010;8(3):196-205.

6. Tinetti ME, Williams CS, Gill TM. Dizziness among older adults: a possible geriatric syndrome. Ann Intern Med. 2000;132(5): 337-344.

7. Drachman DA, Hart CW. An approach to the dizzy patient. Neurology. 1972;22(4):323-334.

8. Branch W. Approach to the patient with dizziness. https://www. uptodate.com/contents/approach-to-the-patient-with-dizziness. Updated Nov 2014.

9. Summary of the Dutch College of General Practitioners' practice guideline 'Dizziness'. https://www.nhg.org/system/files/content/ nhg_org/uploads/standaard/pdf/m75_2.pdf. Updated 2017.

10. Sloane PD, Dallara J, Roach C, Bailey KE, Mitchell M, McNutt R. Management of dizziness in primary care. J Am Board Fam Pract. $1994 ; 7(1): 1-8$.

11. Hanley K, O' Dowd T. Symptoms of vertigo in general practice: a prospective study of diagnosis. Br J Gen Pract. 2002;52(483): 809-812.

12. Stam H, Harting T, Sluijs Mv, et al. Usual care and management of fall risk increasing drugs in older dizzy patients in Dutch general practice. Scand J Prim Health Care. 2016;34(2):165-171.

13. Brandt T, Huppert T, Hüfner K, Zingler VC, Dieterich M, Strupp M. Long-term course and relapses of vestibular and balance disorders. Restor Neurol Neurosci. 2010;28(1):69-82.

14. Strupp M, Dieterich M, Brandt T. The treatment and natural course of peripheral and central vertigo. Dtsch Arztebl Int. 2013;110(29-30): 505-515, quiz 515-516.

15. Obermann M, Bock $E$, Sabev $N$, et al. Long-term outcome of vertigo and dizziness associated disorders following treatment in specialized tertiary care: the Dizziness and Vertigo Registry (DiVeR) Study. J Neurol. 2015;262(9):2083-2091.

16. Dros J, Maarsingh OR, Beem L, et al. Impact of dizziness on everyday life in older primary care patients: a cross-sectional study. Health Qual Life Outcomes. 2011;9:44.

17. Dros J, Maarsingh OR, van der Windt DA, et al. Profiling dizziness in older primary care patients: an empirical study. PLoS One. 2011; 6(1):e16481.

18. Corrales CE, Bhattacharyya N. Dizziness and death: An imbalance in mortality. Laryngoscope. 2016;126(9):2134-2136.

19. Mueller M, Strobl R, Jahn K, Linkohr B, Peters A, Grill E. Burden of disability attributable to vertigo and dizziness in the aged: results from the KORA-Age study. Eur J Public Health. 2014;24(5):802-807.

20. Maarsingh OR, Dros J, van Weert HC, Schellevis FG, Bindels PJ, van der Horst HE. Development of a diagnostic protocol for dizziness in elderly patients in general practice: a Delphi procedure. BMC Fam Pract. 2009;10:12. 
21. Spitzer RL, Kroenke K, Linzer M, et al. Health-related quality of life in primary care patients with mental disorders. Results from the PRIME-MD 1000 Study. JAMA. 1995;274(19):1511-1517.

22. Spitzer RL, Kroenke K, Williams JB. Validation and utility of a selfreport version of PRIME-MD: the PHQ primary care study. Primary Care Evaluation of Mental Disorders. Patient Health Questionnaire. JAMA. 1999;282(18):1737-1744.

23. Jacobson GP, Newman CW. The development of the Dizziness Handicap Inventory. Arch Otolaryngol Head Neck Surg. 1990;116(4): 424-427.

24. Mutlu B, Serbetcioglu B. Discussion of the dizziness handicap inventory. J Vestib Res. 2013;23(6):271-277.

25. Tamber AL, Wilhelmsen KT, Strand LI. Measurement properties of the Dizziness Handicap Inventory by cross-sectional and longitudinal designs. Health Qual Life Outcomes. 2009;7:101.

26. Vereeck L, Truijen S, Wuyts F, Van de Heyning PH. Test-retest reliability of the Dutch version of the Dizziness Handicap Inventory. B-ENT. 2006;2(2):75-80.

27. Vereeck L, Truijen S, Wuyts FL, Van De Heyning PH. Internal consistency and factor analysis of the Dutch version of the Dizziness Handicap Inventory. Acta Otolaryngol. 2007;127(8):788-795.

28. Stam H, Maarsingh OR, Heymans MW, van Weert HCPM, van der Wouden JC, van der Horst HE. Predicting an unfavorable course of dizziness in older patients. Ann Fam Med. 2018;16(5):428-435.

29. Whitney SL, Wrisley DM, Brown KE, Furman JM. Is perception of handicap related to functional performance in persons with vestibular dysfunction? Otol Neurotol. 2004;25(2):139-143.

30. Dros J, Maarsingh OR, Beem L, et al. Functional prognosis of dizziness in older adults in primary care: a prospective cohort study. J Am Geriatr Soc. 2012;60(12):2263-2269.

31. Maarsingh OR, Stam H, van de Ven PM, van Schoor NM, Ridd MJ, van der Wouden JC. Predictors of dizziness in older persons: a 10-year prospective cohort study in the community. BMC Geriatr. 2014;14:133.
32. Gassmann KG, Rupprecht R; IZG Study Group. Dizziness in an older community dwelling population: a multifactorial syndrome. J Nutr Health Aging. 2009;13(3):278-282.

33. Olsson Möller U, Midlöv P, Kristensson J, Ekdahl C, Berglund J, Jakobsson $\mathrm{U}$. Prevalence and predictors of falls and dizziness in people younger and older than 80 years of age - a longitudinal cohort study. Arch Gerontol Geriatr. 2013;56(1):160-168.

34. Leelakanok N, Holcombe AL, Lund BC, Gu X, Schweizer ML. Association between polypharmacy and death: a systematic review and meta-analysis. J Am Pharm Assoc (2003). 2017;57(6):729-38 e10.

35. Pratt LA, Druss BG, Manderscheid RW, Walker ER. Excess mortality due to depression and anxiety in the United States: results from a nationally representative survey. Gen Hosp Psychiatry. 2016;39: 39-45.

36. Twisk JW. Longitudinal data analysis. A comparison between generalized estimating equations and random coefficient analysis. Eur J Epidemiol. 2004;19(8):769-776.

37. Bösner S, Schwarm S, Grevenrath P, et al. Prevalence, aetiologies and prognosis of the symptom dizziness in primary care - a systematic review. BMC Fam Pract. 2018;19(1):33.

38. Austin PC, Mamdani MM, van Walraven C, Tu JV. Quantifying the impact of survivor treatment bias in observational studies. J Eval Clin Pract. 2006;12(6):601-612.

39. Rutjes AW, Reitsma JB, Coomarasamy A, Khan KS, Bossuyt PM. Evaluation of diagnostic tests when there is no gold standard. A review of methods. Health Technol Assess. 2007;11(50):iii, ix-51.

40. Edlow JA, Gurley KL, Newman-Toker DE. A new diagnostic approach to the adult patient with acute dizziness. J Emerg Med. 2018;54(4): 469-483.

41. Newman-Toker DE, Edlow JA. TiTrATE: a novel, evidence-based approach to diagnosing acute dizziness and vertigo. Neurol Clin. 2015;33(3):577-599. 